\title{
MAP Kinases and Prostate Cancer
}

\section{Gonzalo Rodríguez-Berriguete, ${ }^{1}$ Benito Fraile, ${ }^{1}$ Pilar Martínez-Onsurbe, ${ }^{2}$ Gabriel Olmedilla, ${ }^{2}$ Ricardo Paniagua, ${ }^{1}$ and Mar Royuela ${ }^{1}$}

\author{
${ }^{1}$ Department of Cell Biology and Genetics, University of Alcalá, Alcalá de Henares, 28871 Madrid, Spain \\ ${ }^{2}$ Department of Pathology, Príncipe de Asturias Hospital, Alcalá de Henares, 28806 Madrid, Spain
}

Correspondence should be addressed to Mar Royuela, mar.royuela@uah.es

Received 15 June 2011; Accepted 15 August 2011

Academic Editor: Fred Schaper

Copyright (C) 2012 Gonzalo Rodríguez-Berriguete et al. This is an open access article distributed under the Creative Commons Attribution License, which permits unrestricted use, distribution, and reproduction in any medium, provided the original work is properly cited.

\begin{abstract}
The three major mitogen-activated protein kinases (MAPKs) p38, JNK, and ERK are signal transducers involved in a broad range of cell functions including survival, apoptosis, and cell differentiation. Whereas JNK and p38 have been generally linked to cell death and tumor suppression, ERK plays a prominent role in cell survival and tumor promotion, in response to a broad range of stimuli such as cytokines, growth factors, ultraviolet radiation, hypoxia, or pharmacological compounds. However, there is a growing body of evidence supporting that JNK and p38 also contribute to the development of a number of malignances. In this paper we focus on the involvement of the MAPK pathways in prostate cancer, including the less-known ERK5 pathway, as pro- or antitumor mediators, through their effects on apoptosis, survival, metastatic potential, and androgen-independent growth.
\end{abstract}

\section{Introduction}

Mitogen-activated protein kinases (MAPKs) are serine/threonine kinases that mediate intracellular signaling associated with a variety of cellular activities including cell proliferation, differentiation, survival, death, and transformation $[1,2]$. The three main members that integrate the MAPK family in mammalian cells are stress-activated protein kinase cJun NH2-terminal kinase (JNK), stress-activated protein kinase 2 (SAPK2, p38), and the extracellular signal-regulated protein kinases (ERK1/2, p44/p42) (Figure 1). In addition, other less-characterized MAPK pathways exist, such as the extracellular regulated kinase 5 (ERK5) pathway [3, 4] (Figure 1). Albeit with multiple exceptions, JNK and ERK5 are generally associated with apoptosis induction, while ERK1/2 are generally associated to mitogenesis, and inversely related to apoptosis $[3,4]$, and contradictory effects on cell death have been described to p38 [5-12].

In mammalian cells, ERK, p38, and JNK activities are, respectively, regulated by different MAPKs cascades, which provide a link between transmembrane signaling and changes in transcription and that are activated in response to different environmental or developmental signals [4] (Figure 1). Depending on the cell type, a particular MAPK cascade may be involved in different cellular responses. The JNK and $\mathrm{p} 38$ signaling pathways are activated by proinflammatory (TNF $\alpha$, IL-6 or IL-1) or anti-inflammatory (EGF, TGF- $\beta$ ) cytokines, but also in response to cellular stresses such as genotoxic, osmotic, hypoxic, or oxidative stress. The JNK pathway consists of JNK, an MAPKK such as SEK1 (also known as MEK4) or MEK7, and an MAPKKK such as ASK1, MEKK1, mixed-lineage kinase (MLK), or transforming growth factor- $\beta$-activated kinase 1 (TAK1) $[13,14]$. In the p38 signaling pathway, distinct MAPKKs such as MEK3 and MEK6 activate p38, and these can be activated by the same MAPKKKs (such as ASK1 and TAK1) that function in the JNK pathway. In the ERK signaling pathway, ERK1 or ERK2 (ERK1/2) is activated by MEK1/2, which in turn is activated by a Raf isoform such as A-Raf, B-Raf, or Raf1 (also known as C-Raf) and also by TRAF-2 and TRAF-6. The kinase Raf- 1 is activated by the small Ras-like GTPase, whose activation is mediated by the receptor tyrosine kinase (RTK)-Grb2-SOS signaling axis [15]. Members of the Ras family of proteins, including K-Ras, $\mathrm{H}$-Ras, and $\mathrm{N}$-Ras, play a key role in transmission of extracellular signals into cells [16] (Figure 1).

The aim of this paper was to focus on the possible involvement of MAPKs in several transduction pathways 


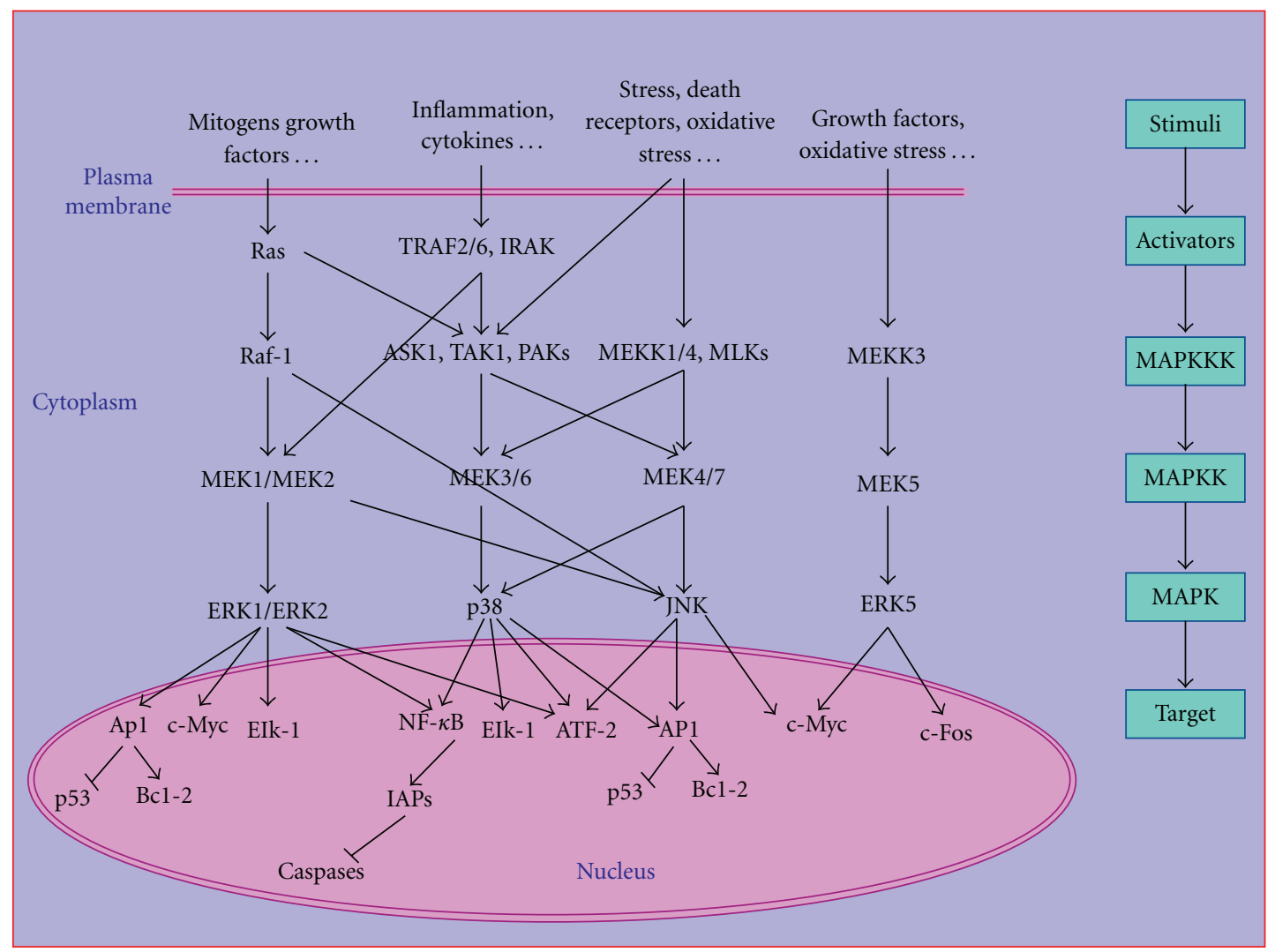

FIGURE 1: Mitogen-activated protein kinase (MAPK) signaling. MAP kinases are activated by upstream kinases such as MAP kinase kinase (MAPKK), that include MEKs 1, 2, 3, 4, 5, 6, and 7. In turn, MAPKKs are activated by several different MAP kinase kinase kinases (MAPKKKs). Numerous stimulatory factors such as cytokines, mitogens, or death receptors can activate MAPKKKs. Each MAPK, depending on the stimulus and cell type, can phosphorylate different transcription factors.

related with prostate cancer development as well as the possible functional role of MAPKs in cell death/survival/ proliferation decisions depending on the cell type, stage, and cell stimulus. We also discuss the possible value of members of these pathways as potential therapeutic targets.

\section{Jun N-Terminal Kinase (JNK)}

JNK proteins, also called stress-activated protein kinases (SAPKs), share a threonine-proline-tyrosine (TPY) motif within their activation loop [17]. They have been involved in development, morphogenesis, and cell differentiation [17]. The earliest discoveries included the identification of the three mammalian JNK genes, namely, JNK1, JNK2, and JNK3 (SAPK- $\gamma$, SAPK- $\alpha$, and SAPK- $\beta$, resp.) which can generate 10 isoforms by alternative splicing $[18,19]$. Alternative splicing further increases the diversity of JNK proteins; however apart from early biochemical studies on these splice forms [16] their functional significance in vivo remains largely unexplored [19]. The products of JNK1 and JNK2 are ubiquitously expressed in almost all cell types and tissues, whereas JNK3 is localized primarily in brain, heart, and testis. Due to their differential expression distribution it is thought that JNK3 presents different functions than
JNK1 and JNK2, whereas these latter may have redundant functions [20]. Investigations on JNKs have focused on their activation in response to diverse extracellular stimuli including ultraviolet (UV) and gamma radiation, inflammatory cytokines (IL-6, IL-1, and TNF), and cytotoxic drugs (Figure 2) $[21,22]$. These stimuli are able to activate JNK through multiple and even overlapping cascades in which participate members of the small Ras-like GTPases or several MAPKKKs (Figure 1). For its complete activation JNK requires dual phosphorylation of threonine and tyrosine residues. MEK4 and MEK7 preferentially phosphorylate at tyrosine and threonine, respectively [23-27], being both MAPKKs needed to fully activate JNK $[4,28]$. Depending on the stimulus and cell type, JNKs phosphorylate different substrates, including transcription factors (AP-1, ATF-2, Elk1, c-Myc, p53, MLK2) and several members of the Bcl-2 family, among others [17, 20, 29] (Figure 1).

Several authors suggest that JNK activity is chronically altered in various cancer types such as those of the prostate $[30,31]$, breast $[32,33]$, pancreas, or lung [34, 35]. Both JNK1 and 2 have been shown to exert pro- as well as antitumor actions in a number of in vivo and in vitro models of malignancies $[6,36]$. A number of findings suggest that in apoptosis JNKs have opposite functions depending on the cellular stimulus and type or even the JNK isoform. 


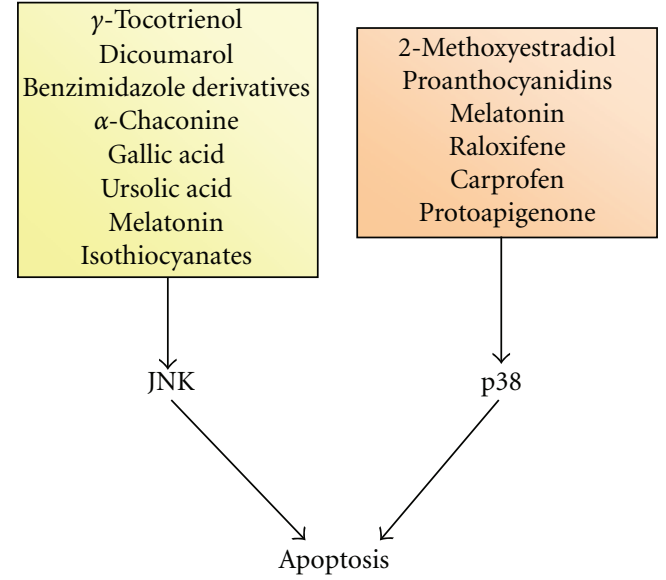

Figure 2: JNK and p38 MAPKs mediate apoptotic cell death induced by a variety of compounds in prostate cancer cells.

Studies into the status of JNK in human prostate tissues are scarce. Both nuclear and total JNK expression seems to be augmented in human malignant prostate epithelium in comparison with normal or benign hyperplasic (BPH) epithelium [30-40]. We are not aware of studies that analyze the activation state of JNK in organ-confined human prostate cancers. Nevertheless in human metastatic lesions, and latestage carcinomas and metastatic deposits from a murine model of prostate cancer, JNK phosphorylated forms seem to be reduced [39, 41, 42].

In spite of its prominent role as a proapoptotic factor, as in other malignances, both pro- and antitumor actions have been attributed to JNK in prostate cancer. Hence, a great number of agents have been shown to trigger apoptosis through JNK. These include gamma-tocotrienol [43], dicoumarol [44], benzimidazole derivatives [45], alphachaconine, gallic acid [34], ursolic acid [35], melatonin [36], and isothiocyanates $[46,47]$ (Figure 2). It is of interest to note that androgen deprivation, the most common therapy used as treatment for advanced prostate cancer, may elicit apoptosis through JNK activation [48]. In the context of its proapoptotic role JNK has been linked to reactive oxygen species (ROS). Some works have highlighted the capability of JNK to trigger apoptosis through ROS production in prostate cancer cells $[49,50]$. Conversely, ROS may induce apoptosis acting through JNK activation. For instance, both genipinand guggulsterone-induced prostate cancer cell apoptoses are caused by ROS-dependent JNK activation [51, 52]. Regarding to its antiapoptotic function, JNKs have been involved in protection from serum starvation-, Fas-, and (at early phase) glucose deprivation-induced apoptosis [53-55].

Besides promoting prostate cancer development by protecting cells from apoptosis, JNK may be involved in prostate cancer metastasis, through its ability to regulate cell adhesion, invasion, and migration. Thus, JNK has been shown to promote the expression of some proteins responsible for extracellular matrix degradation during invasion in prostate cancer cells, such as matrix metalloproteinases (MMPs)-2 and -9 , and urokinase-type plasminogen activator (u-PA) [56-58]. Moreover, Kwon et al. [56] reported that chemical inhibition of JNK in DU145 prostate cancer cells reduces both cell migration and vascular-endothelial growth factor (VEGF) expression, a proangiogenic factor that may facilitate tumor growth and metastasis.

\section{Stress-Activated Protein Kinase 2 (p38)}

p38 family members contain a TGY (threonine-glycinetyrosine) motif in their activation loop. These kinases play roles in cell differentiation, growth, proliferation, survival, and apoptosis [59-61]. Four isoforms of p38 exist, namely, $\mathrm{p} 38 \alpha, \beta, \gamma$, and $\delta$, which exhibit some different functional properties. Whereas $\mathrm{p} 38 \alpha$ and $\mathrm{p} 38 \beta$ are ubiquitously expressed, $\mathrm{p} 38 \gamma$ and $\mathrm{p} 38 \delta$ expression is restricted to some tissues such as muscle, testis, pancreas, lung, kidney, or endocrine glands [62-64]. p38 is activated in cells in response to stress signals, proinflammatory (TNF $\alpha$, IL-6 or IL-1) or anti-inflammatory (EGF, TGF- $\beta$ ) cytokines, UV radiation, and heat and osmotic shock $[59,65]$. A great number of MAPKKs and MAPKKKs (e.g., Mlk1-3, MEKK1-4, TAK, ASK1/2) upstream of $\mathrm{p} 38$ have been identified. Both MAPKKs and MAPKKKs are generally activated by small Ras-like GTPases as Rac1, Cdc42, RhoA, and RhoB [64]. Activated p38 phosphorylates and regulates many transcription factors (including ATF-2, NF- $\kappa$ B, Elk-1, Max, MEF-2, Mac, p53, or Stat1) [65-67] and other cell cycle and apoptotic mediators (e.g., Cdc25A, Bcl-2) [61]. p38 has been shown to enhance cell survival in response to stress stimuli, for instance, in response to DNA damage [61-68]. Triggering of pro- or antiapoptotic p38-mediated response seems to depend on the stimulus, the cell system, and the p38 isoform involved [64].

Several studies suggest that p38 play an important role in leukemia [64], lymphomas [69], and a number of solid malignances such as breast [65], prostate [70], gastric [71], or lung [72] cancers.

Both p38 and its active form p-p38, as well as some upstream kinases (PAK1, MEK6, MEK4), are overexpressed in human cancerous prostatic epithelium $[11,30,41]$. This agrees with the enhanced levels of the phosphorylated form of the well-established p38 substrates Elk-1 and ATF-2 at the same compartment [11]. Uzgare et al. [41], using a transgenic mouse model for prostate cancer, described that p-p38 is overexpressed in prostatic intraepithelial neoplasia (PIN), well-differentiated and moderately differentiated cancers while was reduced or absent in late-stage adenocarcinomas and metastatic deposits. However, like in other tissues, studies focused on p38 function in the prostate malignancy reveal that this MAPK can elicit multiple and even opposite responses, which seem to vary depending on the cell system and context.

A proapoptotic role for $\mathrm{p} 38$ has been established in a number of prostate cancer in vitro models and conditions. p38 promotes apoptosis induced by 2-methoxyestradiol [5], melatonin [6], proanthocyanidins [7], raloxifene [8], carprofen [9], or protoapigenone [10] (Figure 2). By contrast, p38 exerts a protective effect in TNF-induced apoptosis in LNCaP cells, which represents a good model of well-differentiated tumor [11]. 
In spite of having a prominent proapoptotic role p38 may contribute to prostate cancer progression by promoting tumor growth, androgen independence acquisition, and metastasis. It has been proposed that IL-6 may support androgen-independent tumor growth by enhancing androgen receptor (AR) expression/activity. Lin et al. [73] demonstrated that, in turn, the IL-6-induced androgen response depends on p38 activity. p38 seems to play a critical role in hypoxia-reoxygenation-induced increase in AR activity, as well as increased survival, clonogenicity, and invasiveness in prostate cancer cells [74], thus providing additional support for a role for p38 in androgen dependence acquisition. Huang et al. [75] showed in PC3 cells that p38 MAPK is necessary for TGF- $\beta$-mediated activation of MMP- 2 and cell invasion in prostate cancer. Moreover, p38 has been involved in the invasion and migration abilities of the prostate cancer DU145 cells, by enhancing the expression of MMPs-2 and -9, and urokinase-type plasminogen activator (u-PA) [76]. Xu et al. [77] also described MEK4 as a regulator and activator of MMP-2. In agreement, Tang and $\mathrm{Lu}$ [78] found that $\mathrm{p} 38$ activity contributes to adiponectininduced integrin expression and migration capability of human prostate cancer cells. Therefore, and in spite of displaying proapoptotic functions, p38 may constitute a target for prostate cancer treatment given its demonstrated contribution to some prostate cancer hallmarks, as androgen dependence and metastatic phenotype acquisition.

\section{Extracellular Signal-Regulated Protein Kinases (ERK1/2)}

ERK has a threonine-glutamic acid-tyrosine (Thr-Glu-Tyr) motif $[79,80]$ that plays a central role in stimulation of cell proliferation $[81,82]$. The biological consequences of phosphorylation of ERK substrates include increased proliferation, differentiation, survival [83], angiogenesis [84], motility [85], and invasiveness [86]. The two isoforms of ERK, referred to as ERK1 (or p44) and ERK2 (or p42), share $85 \%$ amino acid identity and represent a convergence point for mitogenic signaling from a diverse array of pathways [87-89]. Both are ubiquitously expressed, although their relative abundance in tissues is variable. For example, in many immune cells ERK2 is the predominant species, while in several cells of neuroendocrine origin they may be equally expressed [90].

The ERK pathway is triggered mainly by mitogens and cytokines (Figure 1), acting through receptor tyrosine kinases, G-protein-coupled receptors, and nonnuclear activated steroid hormone receptors $[4,65]$. Most of the signals activating the ERK pathway are initiated through receptor-mediated activation of Ras [4] by stimulating the exchange of GDP bound to Ras for GTP [91]. Then, Ras phosphorylates Raf- 1 . Then, a MAPK cascade is initiated in which Raf- 1 sequentially phosphorylates MEK $1 / 2$ and ERK1/2. Later, ERK1/2 translocate to the nucleus in a process that culminates in modulation of gene transcription through the activation of several transcription factors such as Ets1 [4], ATF-2, c-Fos, c-Myc, Elk-1 [92], or NF- $\kappa$ B [29]
(Figure 1). At the same time, ERK1/2 can also phosphorylate cytoplasmic and nuclear kinases, such as MNK1, MNK2, MPKAP-2, RSK, or MSK1 [90].

TGF- $\beta$ and EGF are growth factors that can induce tumor progression by means of the ERK pathway [93-96]. Several studies showed that these factors are overexpressed in prostate cancer in comparison with normal tissue [9598]. In different tumor cells, expression of some EGF family members such as EGF or TGF- $\alpha$ is associated with poor patient prognosis or resistance to chemotherapeutics [94-99]. IGF-1 and EGF stimulate intracellular signaling pathways converging at the level of ERK2 [100], which is a key kinase mediator of growth-factor-induced mitogenesis in prostate cancer cells [101]. The two major substrates of the IGF-1 receptor, insulin receptor substrate-1 [102] and Shc, are known to contribute to IGF-1-induced activation of ERK [103].

The ERK signaling pathway plays a role in several steps of tumor development [14]. In fact, some components of the Raf-MEK-ERK pathway are activated in solid tumors (such as prostate or breast cancer) and hematological malignances [104-106]. In approximately $30 \%$ of human breast cancers, mutations are found in the ERK1/2 MAPK pathway [65]. ERK1/2 and downstream ERK1/2 targets are hyperphosphorylated in a large subset of mammary tumors [107]. Mutations of K-Ras appear frequently in many cancers including those of the lung and colon [108]. Mutations in the B-Raf gene are responsible for $66 \%$ of malignant melanomas [109]. Increased expressions of Raf pathway has been associated with advanced prostate cancer, hormonal independence, metastasis, and a poor prognosis [110]. Moreover, prostate cancer cell lines isolated from patients with advanced cancer (LNCaP, PC3, DU145) expressed low levels of active Raf kinase inhibitors [105]. TNF- $\alpha$ acts as an ERK activator in some cases related to inflammation and cell proliferation. In this way, Ricote et al. [11] showed that ERK phosphorylation was notably increased by TNF- $\alpha$ in a dose-dependent manner in LNCaP cells. In prostate cancer, presence of Raf- 1 and MEK1 in conjunction with elevated ERK1 and ERK2, and their phosphorylated forms, suggests that stimulation of cell proliferation could be triggered by IL-6 via the ERK pathway [104]. In fact, IL-6 expression increased in prostate cancer in comparison with normal tissue $[104,111]$. Moreover, LNCaP cells which produce IL6 show increased proliferation, at least in part, due to ERK activation [112]. Recently, a phase I clinical trial has revealed the ability of an anti-IL-6 antibody (siltuximab) to inhibit ERK1/2 phosphorylation in prostate tumors [113].

Several investigators suggest associations between decline in ERK activity and advanced malignancy [114, 115]. Conversely Gioeli et al. [116] demonstrated that ERK activation is correlated with tumor malignancy. Junttila et al. [4] demonstrated in the TRAMP mouse model that ERK activation is linked to prostatic epithelial proliferation and initiation of prostate cancer development, while ERK inactivation is correlated with the emergence of a poorly differentiated metastatic and androgen-independent phenotype. Activated ERK mediates activation of the androgen receptor and/or PSA secretion through the growth factor 
receptor tyrosine kinase, Her2/Neu (also known as erbB2) in androgen-independent prostate cancer cells [117]. Other important issue of this pathway in tumor development is that the phosphorylation by ERK of proteins such as myosin, calpain, focal adhesion kinase, and paxillin promotes cancer cell migration. Also, ERK can promote the degradation of extracellular matrix proteins and consequent tumor invasion [14].

ERK may also induce the phosphorylation of apoptotic regulatory molecules including bcl-2 family members (e.g., Bad, Bim, and controversially Bcl-2) and caspase 9 [93]. There are pieces of evidence suggesting a protective effect in cells by NF- $\kappa$ B activation via ERK $[118,119]$. Upon cell stimulation NF- $\kappa \mathrm{B}$ is translocated into the nucleus [120], where it promotes the expression of several antiapoptotic genes such as inhibitors of apoptosis proteins (IAPs) [121] and bcl-2 family members [122].

\section{ERK5}

The fourth MAPK of interest in this paper is ERK5. ERK5 is a large molecular size kinase [123] identified independently by two groups. One used a two-hybrid screen with an upstream activator MEK5 as the bait; the other used a degenerate PCR strategy to clone novel MAPK $[123,124]$. ERK5 is activated by growth factors [125], integrin engagement [126], and cell stress [111] and contributes to expression induction of Ap1 (cJun [127] and Fos [128]), MEF family group (e.g., MEF2C, a well-characterized target [129], and c-Myc [130] transcription factors).

In an in vitro study on androgen-independent PC3 cells, McCracken et al. [131] described ERK5 overexpresion related to proliferative, migrative, and invasive capabilities, establishing the potential importance of ERK5 in aggressive prostate cancer. In other study, Sawhney et al. [126] hypothesized that ERK5 activation could promote cancer metastasis through its ability to regulate cell adhesion and motility.

\section{New Perspectives}

The literature reviewed in this paper suggests that the MAPK transduction pathways are involved in prostate cancer development. The ability of JNK, p38, and ERK to act either as prostate cancer suppressors or promoters depends on the cell type, developmental stage, and specific stimuli. Nevertheless, the molecular roles of these proteins are not known at all. The aim of future studies might be directed towards revealing the factors and mechanisms that account for the differential function of JNK, p38, and ERK MAPKs as pro- or antitumor factors. It may lead to the development of therapeutic approaches to effectively target the protumor effects of the MAPK pathways.

\section{Acknowledgments}

This paper is supported by grants from the "Fundación Mutua Madrileña, 2010 (AP76182010)" (Spain) and the "University of Alcalá-Comunidad Autónoma de Madrid,
Spain (CCG10-UAH/BIO-5985). G. Rodríguez-Berriguete had a predoctoral fellowship from the Alcalá University (Madrid, Spain) during the course of this work.

\section{References}

[1] J. A. McCubrey, M. M. LaHair, and R. A. Franklin, "Reactive oxygen species-induced activation of the MAP kinase signaling pathways," Antioxidants and Redox Signaling, vol. 8, no. 9-10, pp. 1775-1789, 2006.

[2] B. N. Kholodenko and M. R. Birtwistle, "Four-dimensional dynamics of MAPK information processing systems," Wiley Interdisciplinary Reviews. Systems Biology and Medicine, vol. 1, pp. 28-44, 2009.

[3] M. Hayashi and J. D. Lee, "Role of the BMK1/ERK5 signaling pathway: lessons from knockout mice," Journal of Molecular Medicine, vol. 82, no. 12, pp. 800-808, 2004.

[4] M. R. Junttila, S. P. Li, and J. Westermarck, "Phosphatasemediated crosstalk between MAPK signaling pathways in the regulation of cell survival," FASEB Journal, vol. 22, no. 4, pp. 954-965, 2008.

[5] K. Shimada, M. Nakamura, E. Ishida, and N. Konishi, "Molecular roles of MAP kinases and FADD phosphorylation in prostate cancer," Histology and Histopathology, vol. 21, no. 4-6, pp. 415-422, 2006.

[6] S. S. Joo and Y. M. Yoo, "Melatonin induces apoptotic death in LNCaP cells via p38 and JNK pathways: therapeutic implications for prostate cancer," Journal of Pineal Research, vol. 47, no. 1, pp. 8-14, 2009.

[7] P. K. Vayalil, A. Mittal, and S. K. Katiyar, "Proanthocyanidins from grape seeds inhibit expression of matrix metalloproteinases in human prostate carcinoma cells, which is associated with the inhibition of activation of MAPK and NF kappa B," Carcinogenesis, vol. 25, no. 6, pp. 987-995, 2004.

[8] Y. X. Zhang and C. Z. Kong, "The role of mitogen-activated protein kinase cascades in inhibition of proliferation in human prostate carcinoma cells by raloxifene: an in vitro experiment," Zhonghua Yi Xue Za Zhi, vol. 88, no. 4, pp. 271275, 2008.

[9] F. S. Khwaja, E. J. Quann, N. Pattabiraman, S. Wynne, and D. Djakiew, "Carprofen induction of p75NTR-dependent apoptosis via the p38 mitogen-activated protein kinase pathway in prostate cancer cells," Molecular Cancer Therapeutics, vol. 7, no. 11, pp. 3539-3545, 2008.

[10] H. L. Chang, Y. C. Wu, J. H. Su, Y. T. Yeh, and S. S. F. Yuan, "Protoapigenone, a novel flavonoid, induces apoptosis in human prostate cancer cells through activation of p38 mitogen-activated protein kinase and c-Jun NH2-terminal kinase 1/2," Journal of Pharmacology and Experimental Therapeutics, vol. 325, no. 3, pp. 841-849, 2008.

[11] M. Ricote, I. García-Tuñón, B. Fraile et al., "P38 MAPK protects against TNF- $\alpha$-provoked apoptosis in LNCaP prostatic cancer cells," Apoptosis, vol. 11, no. 11, pp. 1969-1975, 2006.

[12] G. Rodríguez-Berriguete, B. Fraile, R. Paniagua, P. Aller, and M. Royuela, "Expression of NF- $\kappa$ B-related proteins and their modulation during TNF- $\alpha$-provoked apoptosis in prostate cancer cells," submitted to Prostate.

[13] R. J. Davis, "Signal transduction by the JNK group of MAP kinases," Cell, vol. 103, no. 2, pp. 239-252, 2000.

[14] E. K. Kim and E. J. Choi, "Pathological roles of MAPK signaling pathways in human diseases," Biochimica et Biophysica Acta, vol. 1802, no. 4, pp. 396-405, 2010. 
[15] A. S. Dhillon, S. Hagan, O. Rath, and W. Kolch, "MAP kinase signalling pathways in cancer," Oncogene, vol. 26, no. 22, pp. 3279-3290, 2007.

[16] B. B. Ancrile, K. M. O’Hayer, and C. M. Counter, “Oncogenic ras-induced expression of cytokines: a new target of anticancer therapeutics," Molecular Interventions, vol. 8, no. 1, pp. 22-27, 2008.

[17] L. E. Heasley and S. Y. Han, "JNK regulation of oncogenesis," Molecules and Cells, vol. 21, no. 2, pp. 167-173, 2006.

[18] B. Derijard, M. Hibi, I. H. Wu et al., "JNK1: a protein kinase stimulated by UV light and Ha-Ras that binds and phosphorylates the c-Jun activation domain," Cell, vol. 76, no. 6, pp. 1025-1037, 1994.

[19] M. A. Bogoyevitch, K. R. W. Ngoei, T. T. Zhao, Y. Y. C. Yeap, and D. C. H. Ng, "c-Jun N-terminal kinase (JNK) signaling: recent advances and challenges," Biochimica et Biophysica Acta, vol. 1804, no. 3, pp. 463-475, 2010.

[20] A. M. Bode and Z. Dong, "The functional contrariety of JNK," Molecular Carcinogenesis, vol. 46, no. 8, pp. 591-598, 2007.

[21] H. Khalaf, J. Jass, and P. E. Olsson, "Differential cytokine regulation by NF-kappaB and AP-1 in Jurkat T-cells," $B M C$ Immunology, vol. 11, article 26, 2010.

[22] F. De Graeve, A. Bahr, K. T. Sabapathy et al., "Role of the ATFa/JNK2 complex in Jun activation," Oncogene, vol. 18, no. 23, pp. 3491-3500, 1999.

[23] I. Sanchez, R. T. Hughes, B. J. Mayer et al., "Role of SAPK/ERK kinase-1 in the stress-activated pathway regulating transcription factor c-jun," Nature, vol. 372, no. 6508, pp. 794-800, 1994.

[24] S. Lawler, Y. Fleming, M. Goedert, and P. Cohen, "Synergistic activation of SAPK1/JNK1 by two MAP kinase kinases in vitro," Current Biology, vol. 8, no. 25, pp. 1387-1390, 1998.

[25] Y. Fleming, C. G. Armstrong, N. Morrice, A. Paterson, M. Goedert, and P. Cohen, "Synergistic activation of stress-activated protein kinase $1 / \mathrm{c}$-Jun $\mathrm{N}$-terminal kinase (SAPK1/JNK) isoforms by mitogen-activated protein kinase kinase 4 (MKK4) and MKK7," Biochemical Journal, vol. 352, no. 1, pp. 145-154, 2000.

[26] T. Wada, K. Nakagawa, T. Watanabe et al., "Impaired synergistic activation of stress-activated protein kinase SAPK/JNK in mouse embryonic stem cells lacking SEK1/MKK4," Journal of Biological Chemistry, vol. 276, no. 33, pp. 30892-30897, 2001.

[27] X. Wang, B. Nadarajah, A. C. Robinson et al., "Targeted deletion of the mitogen-activated protein kinase kinase 4 gene in the nervous system causes severe brain developmental defects and premature death," Molecular and Cellular Biology, vol. 27, no. 22, pp. 7935-7946, 2007.

[28] C. Tournier, C. Dong, T. K. Turner, S. N. Jones, R. A. Flavell, and R. J. Davis, "MKK7 is an essential component of the JNK signal transduction pathway activated by proinflammatory cytokines," Genes and Development, vol. 15, no. 11, pp. 14191426, 2001.

[29] A. G. Turjanski, J. P. Vaqué, and J. S. Gutkind, "MAP kinases and the control of nuclear events," Oncogene, vol. 26, no. 22, pp. 3240-3253, 2007.

[30] M. Royuela, M. I. Arenas, F. R. Bethencourt, B. Fraile, and R. Paniagua, "Regulation of proliferation/apoptosis equilibrium by mitogen-activated protein kinases in normal, hyperplastic, and carcinomatous human prostate," Human Pathology, vol. 33, no. 3, pp. 299-306, 2002.
[31] J. Meshki, M. C. Caino, V. A. von Burstin, E. Griner, and M. G. Kazanietz, "Regulation of prostate cancer cell survival by protein kinase $\mathrm{C} \varepsilon$ involves bad phosphorylation and modulation of the TNF $\alpha$ /JNK pathway," Journal of Biological Chemistry, vol. 285, no. 34, pp. 26033-26040, 2010.

[32] H. Y. Wang, Z. Cheng, and C. C. Malbon, "Overexpression of mitogen-activated protein kinase phosphatases MKP1, MKP2 in human breast cancer," Cancer Letters, vol. 191, no. 2, pp. 229-237, 2003.

[33] J. Wang, I. Kuiatse, A. V. Lee, J. Pan, A. Giuliano, and X. Cui, "Sustained c-Jun-NH2-kinase activity promotes epithelial-mesenchymal transition, invasion, and survival of breast cancer cells by regulating extracellular signal-regulated kinase activation," Molecular Cancer Research, vol. 8, no. 2, pp. 266-277, 2010.

[34] G. H. Su, W. Hilgers, M. C. Shekher et al., "Alterations in pancreatic, biliary, and breast carcinomas support MKK4 as a genetically targeted tumor suppressor gene," Cancer Research, vol. 58, no. 11, pp. 2339-2342, 1998.

[35] J. J. Lee, J. H. Lee, Y. G. Ko, S. I. Hong, and J. S. Lee, "Prevention of premature senescence requires JNK regulation of Bcl-2 and reactive oxygen species," Oncogene, vol. 29, no. 4, pp. 561-575, 2010.

[36] O. Potapova, M. Gorospe, F. Bost et al., "c-Jun N-terminal kinase is essential for growth of human T98G glioblastoma cells," Journal of Biological Chemistry, vol. 275, no. 32, pp. 24767-24775, 2000.

[37] N. Chen, M. Nomura, Q. B. She et al., "Suppression of skin tumorigenesis in c-Jun $\mathrm{NH}(2)$-terminal kinase-2-deficient mice," Cancer Research, vol. 61, no. 10, pp. 3908-3912, 2001.

[38] Q. B. She, N. Chen, A. M. Bode, R. A. Flavell, and Z. Dong, "Deficiency of c-Jun-NH(2)-terminal kinase1 in mice enhances skin tumor development by $12-\mathrm{O}-$ tetradecanoylphorbol-13-acetate," Cancer Research, vol. 62, no. 5, pp. 1343-1348, 2002.

[39] H. Takahashi, H. Ogata, R. Nishigaki, D. H. Broide, and M. Karin, "Tobacco smoke promotes lung tumorigenesis by triggering IKKbeta- and JNK1-dependent inflammation," Cancer Cell, vol. 17, no. 1, pp. 89-97, 2010.

[40] C. Magi-Galluzzi, R. Mishra, M. Fiorentino et al., "Mitogenactivated protein kinase phosphatase 1 is overexpressed in prostate cancers and is inversely related to apoptosis," Laboratory Investigation, vol. 76, no. 1, pp. 37-51, 1997.

[41] A. R. Uzgare, P. J. Kaplan, and N. M. Greenberg, "Differential expression and/or activation of p38MAPK, erk1/2, and jnk during the initiation and progression of prostate cancer," Prostate, vol. 55, no. 2, pp. 128-139, 2003.

[42] R. L. Grubb, J. Deng, P. A. Pinto et al., "Pathway biomarker profiling of localized and metastatic human prostate cancer reveal metastatic and prognostic signatures," Journal of Proteome Research, vol. 8, no. 6, pp. 3044-3054, 2009.

[43] W. N. Yap, P. N. Chang, H. Y. Han et al., “ $\gamma$-tocotrienol suppresses prostate cancer cell proliferation and invasion through multiple-signalling pathways," The British Journal of Cancer, vol. 99, no. 11, pp. 1832-1841, 2008.

[44] J. Watanabe, H. Nishiyama, Y. Matsui et al., "Dicoumarol potentiates cisplatin-induced apoptosis mediated by c-Jun N-terminal kinase in p53 wild-type urogenital cancer cell lines," Oncogene, vol. 25, no. 17, pp. 2500-2508, 2006.

[45] W. L. Chang, C. S. Chang, P. C. Chiang et al., "2Phenyl-5-(pyrrolidin-1-yl)-1-(3,4,5-trimethoxybenzyl)-1Hbenzimidazole, a benzimidazole derivative, inhibits growth of human prostate cancer cells by affecting tubulin and c-Jun 
N-terminal kinase," The British Journal of Pharmacology, vol. 160, no. 7, pp. 1677-1689, 2010.

[46] Y. R. Chen, J. Han, R. Kori, A. N. Tony Kong, and T. H. Tan, "Phenylethyl isothiocyanate induces apoptotic signaling via suppressing phosphatase activity against c-Jun N-terminal kinase," Journal of Biological Chemistry, vol. 277, no. 42, pp. 39334-39342, 2002.

[47] C. Xu, G. Shen, X. Yuan et al., "ERK and JNK signaling pathways are involved in the regulation of activator protein 1 and cell death elicited by three isothiocyanates in human prostate cancer PC-3 cells," Carcinogenesis, vol. 27, no. 3, pp. 437-445, 2006.

[48] P. I. Lorenzo and F. Saatcioglu, "Inhibition of apoptosis in prostate cancer cells by androgens is mediated through downregulation of c-Jun N-terminal kinase activation," Neoplasia, vol. 10, no. 5, pp. 418-428, 2008.

[49] J. Antosiewicz, W. Ziolkowski, J. J. Kaczor, and A. HermanAntosiewicz, "Tumor necrosis factor- $\alpha$-induced reactive oxygen species formation is mediated by JNK1-dependent ferritin ç degradation and elevation of labile iron pool," Free Radical Biology and Medicine, vol. 43, no. 2, pp. 265-270, 2007.

[50] A. M. Sánchez, S. Malagarie-Cazenave, N. Olea, D. Vara, A. Chiloeches, and I. Díaz-Laviada, "Apoptosis induced by capsaicin in prostate PC-3 cells involves ceramide accumulation, neutral sphingomyelinase, and JNK activation," Apoptosis, vol. 12, no. 11, pp. 2013-2024, 2007.

[51] S. V. Singh, S. Choi, Y. Zeng, E. R. Hahm, and D. Xiao, "Guggulsterone-induced apoptosis in human prostate cancer cells is caused by reactive oxygen intermediate dependent activation of c-Jun NH2-terminal kinase," Cancer Research, vol. 67, no. 15, pp. 7439-7449, 2007.

[52] H. Y. Hong and B. C. Kim, "Mixed lineage kinase 3 connects reactive oxygen species to c-Jun $\mathrm{NH} 2$-terminal kinaseinduced mitochondrial apoptosis in genipin-treated PC3 human prostate cancer cells," Biochemical and Biophysical Research Communications, vol. 362, no. 2, pp. 307-312, 2007.

[53] S. Yang, M. Lim, L. K. Pham et al., "Bone morphogenetic protein 7 protects prostate cancer cells from stress-induced apoptosis via both Smad and c-Jun NH2-terminal kinase pathways," Cancer Research, vol. 66, no. 8, pp. 4285-4290, 2006.

[54] J. F. Curtin and T. G. Cotter, "JNK regulates HIPK3 expression and promotes resistance to Fas-mediated apoptosis in DU 145 prostate carcinoma cells," Journal of Biological Chemistry, vol. 279, no. 17, pp. 17090-17100, 2004.

[55] H. Yun, H. S. Kim, S. Lee et al., "AMP kinase signaling determines whether c-Jun $\mathrm{N}$-terminal kinase promotes survival or apoptosis during glucose deprivation," Carcinogenesis, vol. 30, no. 3, pp. 529-537, 2009.

[56] G. T. Kwon, H. J. Cho, W. Y. Chung, K. K. Park, A. Moon, and J. H. Y. Park, "Isoliquiritigenin inhibits migration and invasion of prostate cancer cells: possible mediation by decreased JNK/AP-1 signaling," Journal of Nutritional Biochemistry, vol. 20, no. 9, pp. 663-676, 2009.

[57] S. H. Hung, K. H. Shen, C. H. Wu, C. L. Liu, and Y. W. Shih, " $\alpha$-mangostin suppresses PC-3 human prostate carcinoma cell metastasis by inhibiting matrix metalloproteinase-2/9 and urokinase-plasminogen expression through the JNK signaling pathway," Journal of Agricultural and Food Chemistry, vol. 57, no. 4, pp. 1291-1298, 2009.

[58] C. S. Chien, K. H. Shen, J. S. Huang, S. C. Ko, and Y. W. Shih, "Antimetastatic potential of fisetin involves inactivation of the PI3K/Akt and JNK signaling pathways with downregulation of MMP-2/9 expressions in prostate cancer PC-3 cells," Molecular and Cellular Biochemistry, vol. 333, no. 1-2, pp. 169-180, 2010.

[59] J. Raingeaud, S. Gupta, J. S. Rogers et al., "Pro-inflammatory cytokines and environmental stress cause p38 mitogenactivated protein kinase activation by dual phosphorylation on tyrosine and threonine," Journal of Biological Chemistry, vol. 270, no. 13, pp. 7420-7426, 1995.

[60] L. Hui, L. Bakiri, E. Stepniak, and E. F. Wagner, "p38 $\alpha$ : a suppressor of cell proliferation and tumorigenesis," Cell Cycle, vol. 6, no. 20, pp. 2429-2433, 2007.

[61] T. M. Thornton and M. Rincon, "Non-classical p38 map kinase functions: cell cycle checkpoints and survival," International Journal of Biological Sciences, vol. 5, no. 1, pp. 44-51, 2009.

[62] Y. Jiang, Z. Li, E. M. Schwarz et al., "Structure-function studies of p38 mitogen-activated protein kinase. Loop 12 influences substrate specificity and autophosphorylation, but not upstream kinase selection," Journal of Biological Chemistry, vol. 272, no. 17, pp. 11096-11102, 1997.

[63] X. S. Wang, K. Diener, C. L. Manthey et al., "Molecular cloning and characterization of a novel p38 mitogenactivated protein kinase," Journal of Biological Chemistry, vol. 272, no. 38, pp. 23668-23674, 1997.

[64] Y. Feng, J. Wen, and C. C. Chang, "p38 mitogen-activated protein kinase and hematologic malignancies," Archives of Pathology and Laboratory Medicine, vol. 133, no. 11, pp. 1850-1856, 2009.

[65] J. Whyte, O. Bergin, A. Bianchi, S. McNally, and F. Martin, "Key signalling nodes in mammary gland development and cancer. Mitogen-activated protein kinase signalling in experimental models of breast cancer progression and in mammary gland development," Breast Cancer Research, vol. 11, no. 5, p. 209, 2009.

[66] M. Zhao, L. New, V. V. Kravchenko et al., "Regulation of the MEF2 family of transcription factors by p38," Molecular and Cellular Biology, vol. 19, no. 1, pp. 21-30, 1999.

[67] M. Royuela, G. Rodríguez-Berriguete, B. Fraile, and R. Paniagua, "TNF- $\alpha / \mathrm{IL}-1 / \mathrm{NF}-\kappa \mathrm{B}$ transduction pathway in human cancer prostate," Histology and Histopathology, vol. 23, no. 10, pp. 1279-1290, 2008.

[68] C. D. Wood, T. M. Thornton, G. Sabio, R. A. Davis, and M. Rincon, "Nuclear localization of p38 MAPK in response to DNA damage," International Journal of Biological Sciences, vol. 5, no. 5, pp. 428-437, 2009.

[69] B. Zheng, P. Flumara, Y. V. Li et al., "MEK/ERK pathway is aberrantly active in Hodgkin disease: a signaling pathway shared by CD30, CD40, and RANK that regulates cell proliferation and survival," Blood, vol. 102, no. 3, pp. 10191027, 2003.

[70] M. Ricote, I. García-Tuñón, F. Bethencourt et al., "The p38 transduction pathway in prostatic neoplasia," Journal of Pathology, vol. 208, no. 3, pp. 401-407, 2006.

[71] X. Guo, N. Ma, J. Wang et al., "Increased p38-MAPK is responsible for chemotherapy resistance in human gastric cancer cells," BMC cancer, vol. 8, p. 375, 2008.

[72] C. Zhang, H. Zhu, X. Yang et al., "P53 and p38 MAPK pathways are involved in MONCPT-induced cell cycle G2/M arrest in human non-small cell lung cancer A549," Journal of Cancer Research and Clinical Oncology, vol. 136, no. 3, pp. 437-445, 2010. 
[73] D. L. Lin, M. C. Whitney, Z. Yao, and E. T. Keller, "Interleukin-6 induces androgen responsiveness in prostate cancer cells through up-regulation of androgen receptor expression," Clinical Cancer Research, vol. 7, no. 6, pp. 17731781, 2001.

[74] L. Khandrika, R. Lieberman, S. Koul et al., "Hypoxiaassociated p38 mitogen-activated protein kinase-mediated androgen receptor activation and increased HIF- $1 \alpha$ levels contribute to emergence of an aggressive phenotype in prostate cancer," Oncogene, vol. 28, no. 9, pp. 1248-1260, 2009.

[75] X. Huang, S. Chen, L. Xu et al., "Genistein inhibits p38 map kinase activation, matrix metalloproteinase type 2 , and cell invasion in human prostate epithelial cells," Cancer Research, vol. 65 , no. 8, pp. 3470-3478, 2005.

[76] K. H. Shen, S. H. Hung, L. T. Yin et al., "Acacetin, a flavonoid, inhibits the invasion and migration of human prostate cancer DU145 cells via inactivation of the p38 MAPK signaling pathway," Molecular and Cellular Biochemistry, vol. 333, no. 1-2, pp. 279-291, 2010.

[77] L. Xu, Y. Ding, W. J. Catalona et al., "MEK4 function, genistein treatment, and invasion of human prostate cancer cells," Journal of the National Cancer Institute, vol. 101, no. 16, pp. 1141-1155, 2009.

[78] C. H. Tang and M. E. Lu, "Adiponectin increases motility of human prostate cancer cells via AdipoR, p38, AMPK, and NF- $\kappa$ B pathways," Prostate, vol. 69, no. 16, pp. 1781-1789, 2009.

[79] T. Hunter, "Signaling_-2000 and beyond," Cell, vol. 100, no. 1, pp. 113-127, 2000.

[80] Y. Liu, L. Formisano, I. Savtchouk et al., "A single fearinducing stimulus induces a transcription-dependent switch in synaptic AMPAR phenotype," Nature Neuroscience, vol. 13, no. 2, pp. 223-231, 2010.

[81] R. Marais and C. J. Marshall, "Control of the ERK MAP kinase cascade by ras and raf," Cancer Surveys, vol. 27, pp. 101-125, 1996.

[82] S. Peng, Y. Zhang, J. Zhang, H. Wang, and B. Ren, "ERK in learning and memory: a review of recent research," International Journal of Molecular Sciences, vol. 11, no. 1, pp. 222-232, 2010.

[83] G. Pearson, F. Robinson, T. B. Gibson et al., "Mitogenactivated protein (MAP) kinase pathways: regulation and physiological functions," Endocrine Reviews, vol. 22, no. 2, pp. 153-183, 2001.

[84] G. Pagès, J. Milanini, D. E. Richard et al., "Signaling angiogenesis via p42/p44 MAP kinase cascade," Annals of the New York Academy of Sciences, vol. 902, pp. 187-200, 2000.

[85] E. J. Joslin, L. K. Opresko, A. Wells, H. S. Wiley, and D. A. Lauffenburger, "EGF-receptor-mediated mammary epithelial cell migration is driven by sustained ERK signaling from autocrine stimulation," Journal of Cell Science, vol. 120, no. 20, pp. 3688-3699, 2007.

[86] D. J. Price, S. Avraham, J. Feuerstein, Y. Fu, and H. K. Avraham, "The invasive phenotype in HMT-3522 cells requires increased EGF receptor signaling through both PI 3-kinase and ERK 1,2 pathways," Cell Communication and Adhesion, vol. 9, no. 2, pp. 87-102, 2002.

[87] P. J. Cullen and P. J. Lockyer, "Integration of calcium and Ras signalling," Nature Reviews Molecular Cell Biology, vol. 3, no. 5, pp. 339-348, 2002.

[88] D. A. Eisinger and H. Ammer, " $\delta$-opioid receptors activate ERK/MAP kinase via integrin-stimulated receptor tyrosine kinases," Cellular Signalling, vol. 20, pp. 2324-2331, 2008.
[89] L. Gao, L. Chao, and J. Chao, "A novel signaling pathway of tissue kallikrein in promoting keratinocyte migration: activation of proteinase-activated receptor 1 and epidermal growth factor receptor," Experimental Cell Research, vol. 316, no. 3, pp. 376-389, 2010.

[90] A. Zebisch, A. P. Czernilofsky, G. Keri, J. Smigelskaite, H. Sill, and J. Troppmair, "Signaling through RAS-RAF-MEK-ERK: from basics to bedside," Current Medicinal Chemistry, vol. 14, no. 5, pp. 601-623, 2007.

[91] J. S. Silver and C. A. Hunter, "gp130 at the nexus of inflammation, autoimmunity, and cancer," Journal of Leukocyte Biology, vol. 88, no. 6, pp. 1145-1156, 2010.

[92] G. Werlen, B. Hausmann, D. Naeher, and E. Palmer, "Signaling life and death in the thymus: timing is everything," Science, vol. 299, no. 5614, pp. 1859-1863, 2003.

[93] N. Thakur, A. Sorrentino, C. H. Heldin, and M. Landström, "TGF- $\beta$ uses the E3-ligase TRAF6 to turn on the kinase TAK1 to kill prostate cancer cells," Future Oncology, vol. 5, no. 1, pp. 1-3, 2009.

[94] K. J. Wilson, J. L. Gilmore, J. Foley, M. A. Lemmon, and D. J. Riese, "Functional selectivity of EGF family peptide growth factors: implications for cancer," Pharmacology and Therapeutics, vol. 122, no. 1, pp. 1-8, 2009.

[95] M. P. De Miguel, M. Royuela, F. R. Bethencourt, L. Santamaria, B. Fraile, and R. Paniagua, "Immuno-expression of tumor necrosis factor-a and its receptors 1 and 2 correlates with proliferation/apoptosis equilibrium in normal, hyperplasic and carcinomatous human prostate," Cytokine, vol. 5, pp. 535-538, 2000.

[96] M. Royuela, M. P. De Miguel, F. R. Bethencourt, M. SanchezChapado, B. Fraile, and R. Paniagua, "Transforming growth factor $\beta 1$ and its receptor types I and II. Comparison in human normal prostate, benign prostatic hyperplasia, and prostatic carcinoma," Growth Factors, vol. 16, no. 2, pp. 101110, 1998.

[97] I. Leav, J. E. McNeal, J. Ziar, and J. Alroy, "The localization of transforming growth factor alpha and epidermal growth factor receptor in stromal and epithelial compartments of developing human prostate and hyperplastic, dysplastic, and carcinomatous lesions," Human Pathology, vol. 29, no. 7, pp. 668-675, 1998.

[98] M. R. Cardillo, E. Petrangeli, L. Perracchio, L. Salvatori, L. Ravenna, and F. Di Silverio, "Transforming growth factor-beta expression in prostate neoplasia," Analytical \& Quantitative Cytology \& Histology, vol. 22, pp. 1-10, 2000.

[99] N. Eckstein, K. Servan, L. Girard et al., "Epidermal growth factor receptor pathway analysis identifies amphiregulin as a key factor for cisplatin resistance of human breast cancer cells," Journal of Biological Chemistry, vol. 283, no. 2, pp. 739750, 2008.

[100] T. Putz, Z. Culig, I. E. Eder et al., "Epidermal growth factor (EGF) receptor blockade inhibits the action of EGF, insulinlike growth factor I, and a protein kinase A activator on the mitogen-activated protein kinase pathway in prostate cancer cell lines," Cancer Research, vol. 59, no. 1, pp. 227-233, 1999.

[101] P. L. De Souza, M. Castillo, and C. E. Myers, "Enhancement of paclitaxel activity against hormone-refractory prostate cancer cells in vitro and in vivo by quinacrine," The British Journal of Cancer, vol. 75, no. 11, pp. 1593-1600, 1997.

[102] H. Y. Chang, H. Nishitoh, X. Yang, H. Ichijo, and D. Baltimore, "Activation of apoptosis signal-regulating kinase 1 (ASK1) by the adapter protein Daxx," Science, vol. 281, no. 5384, pp. 1860-1863, 1998. 
[103] M. Dews, M. Prisco, F. Peruzzi, G. Romano, A. Morrione, and R. Baserga, "Domains of the insulin-like growth factor I receptor required for the activation of extracellular signalregulated kinases," Endocrinology, vol. 141, no. 4, pp. 1289 1300, 2000.

[104] G. Rodriguez-Berriguete, A. Prieto, B. Fraile et al., "Relationship between IL-6/ERK and NF- $\kappa$ B: a study in normal and pathological human prostate gland (benign hyperplasia, intraepithelial neoplasia and cancer)," European Cytokine Network, vol. 21, no. 4, pp. 241-250, 2010.

[105] J. A. McCubrey, L. S. Steelman, W. H. Chappell et al., "Roles of the Raf/MEK/ERK pathway in cell growth, malignant transformation and drug resistance," Biochim Biophys Acta, vol. 1773, pp. 1263-1284, 2007.

[106] S. Grant, "Cotargeting survival signaling pathways in cancer," Journal of Clinical Investigation, vol. 118, no. 9, pp. 30033006, 2008.

[107] H. Mueller, N. Flury, S. Eppenberger-Castori, W. Kueng, F. David, and U. Eppenberger, "Potential prognostic value of mitogen-activated protein kinase activity for disease-free survival of primary breast cancer patients," International Journal of Cancer, vol. 89, no. 4, pp. 384-388, 2000.

[108] S. Schubbert, K. Shannon, and G. Bollag, "Hyperactive ras in developmental disorders and cancer," Nature Reviews Cancer, vol. 7, no. 4, pp. 295-308, 2007.

[109] E. Halilovic and D. B. Solit, "Therapeutic strategies for inhibiting oncogenic BRAF signaling," Current Opinion in Pharmacology, vol. 8, no. 4, pp. 419-426, 2008.

[110] E. T. Keller, Z. Fu, K. Yeung, and M. Brennan, "Raf kinase inhibitor protein: a prostate cancer metastasis suppressor gene," Cancer Letters, vol. 207, no. 2, pp. 131-137, 2004.

[111] B. Wegiel, A. Bjartell, Z. Culig, and J. L. Persson, "Interleukin6 activates PI3K/Akt pathway and regulates cyclin A1 to promote prostate cancer cell survival," International Journal of Cancer, vol. 122, no. 7, pp. 1521-1529, 2008.

[112] J. Karkera, H. Steiner, W. Li et al., "The anti-interleukin6 antibody siltuximab down-regulates genes implicated in tumorigenesis in prostate cancer patients from a phase I study," Prostate, vol. 71, pp. 1455-1465, 2011.

[113] H. Steiner, S. Godoy-Tundidor, H. Rogatsch et al., "Accelerated in vivo growth of prostate tumors that up-regulate interleukin- 6 is associated with reduced retinoblastoma protein expression and activation of the mitogen-activated protein kinase pathway," The American Journal of Pathology, vol. 162, no. 2, pp. 655-663, 2003.

[114] C. P. Pjaweletz, L. Charboneau, V. E. Bichsel et al., "Reverse phase protein microarrays which capture disease progression show activation of pro-survival pathways at the cancer invasion front," Oncogene, vol. 20, no. 16, pp. 1981-1989, 2001.

[115] S. N. Malik, M. Brattain, P. M. Ghosh et al., "Immunohistochemical demonstration of phospho-Akt in high Gleason grade prostate cancer," Clinical Cancer Research, vol. 8, no. 4, pp. 1168-1171, 2002.

[116] D. Gioeli, J. W. Mandell, G. R. Petroni, H. F. Frierson, and M. J. Weber, "Activation of mitogen-activated protein kinase associated with prostate cancer progression," Cancer Research, vol. 59, no. 2, pp. 279-284, 1999.

[117] M. E. Grossmann, H. Huang, and D. J. Tindall, "Androgen receptor signaling in androgen-refractory prostate cancer," Journal of the National Cancer Institute, vol. 93, no. 22, pp. 1687-1697, 2001.
[118] Y. Zhu, C. Culmsee, S. Klumpp, and J. Krieglstein, "Neuroprotection by transforming growth factor- $\beta 1$ involves activation of nuclear factor- $\kappa \mathrm{B}$ through phosphatidylinositol$3-\mathrm{OH}$ kinase/Akt and mitogen-activated protein kinaseextracellular-signal regulated kinase1,2 signaling pathways," Neuroscience, vol. 123, no. 4, pp. 897-906, 2004.

[119] L. F. Chu, W. T. Wang, V. K. Ghanta, C. H. Lin, Y. Y. Chiang, and C. M. Hsueh, "Ischemic brain cell-derived conditioned medium protects astrocytes against ischemia through GDNF/ERK/NF- $\kappa$ B signaling pathway," Brain Research, vol. 1239, pp. 24-35, 2008.

[120] M. Karin, "Nuclear factor- $\kappa \mathrm{B}$ in cancer development and progression," Nature, vol. 441, no. 7092, pp. 431-436, 2006.

[121] G. Rodriguez-Berriguete, B. Fraile, F. R. de Bethencourt et al., "Role of IAPs in prostate cancer progression: immunohistochemical study in normal and pathological (benign hyperplastic, prostatic intraepithelial neoplasia and cancer) human prostate," BMC Cancer, vol. 10, p. 18, 2010.

[122] B. B. Aggarwal, "Tumour necrosis factors receptor associated signalling molecules and their role in activation of apoptosis, JNK and NF- $\kappa \mathrm{B}$," Annals of the Rheumatic Diseases, vol. 59, no. 1, pp. i6-i16, 2000.

[123] J. D. Lee, R. J. Ulevitch, and J. Han, "Primary structure of BMK1: a new mammalian map kinase," Biochemical and Biophysical Research Communications, vol. 213, pp. 715-724, 1995.

[124] G. Zhou, Zhao Qin Bao, and J. E. Dixon, "Components of a new human protein kinase signal transduction pathway," Journal of Biological Chemistry, vol. 270, no. 21, pp. 1266512669, 1995.

[125] Y. Kato, R. I. Tapping, S. Huang, M. H. Watson, R. J. Ulevitch, and J. D. Lee, "Bmk1/Erk5 is required for cell proliferation induced by epidermal growth factor," Nature, vol. 395, no. 6703, pp. 713-716, 1998.

[126] R. S. Sawhney, W. Liu, and M. G. Brattain, "A novel role of ERK5 in integrin-mediated cell adhesion and motility in cancer cells via Fak signaling," Journal of Cellular Physiology, vol. 219, no. 1, pp. 152-161, 2009.

[127] M. Kayahara, X. Wang, and C. Tournier, "Selective regulation of c-jun gene expression by mitogen-activated protein kinases via the 12-o-tetradecanoylphorbol-13-acetateresponsive element and myocyte enhancer factor 2 binding sites," Molecular and Cellular Biology, vol. 25, no. 9, pp. 37843792, 2005.

[128] S. Kamakura, T. Moriguchi, and E. Nishida, "Activation of the protein kinase ERK5/BMK1 by receptor tyrosine kinases. Identification and characterization of a signalling pathway to the nucleus," Journal of Biological Chemistry, vol. 274, no. 37, pp. 26563-26571, 1999.

[129] Y. Kato, V. V. Kravchenko, R. I. Tapping, J. Han, R. J. Ulevitch, and J. D. Lee, "BMK1/ERK5 regulates seruminduced early gene expression through transcription factor MEF2C," EMBO Journal, vol. 16, no. 23, pp. 7054-7066, 1997.

[130] J. M. English, G. Pearson, R. Baer, and M. H. Cobb, "Identification of substrates and regulators of the mitogen-activated protein kinase ERK5 using chimeric protein kinases," Journal of Biological Chemistry, vol. 273, no. 7, pp. 3854-3860, 1998.

[131] S. R. C. McCracken, A. Ramsay, R. Heer et al., "Aberrant expression of extracellular signal-regulated kinase 5 in human prostate cancer," Oncogene, vol. 27, no. 21, pp. 2978 2988, 2008. 

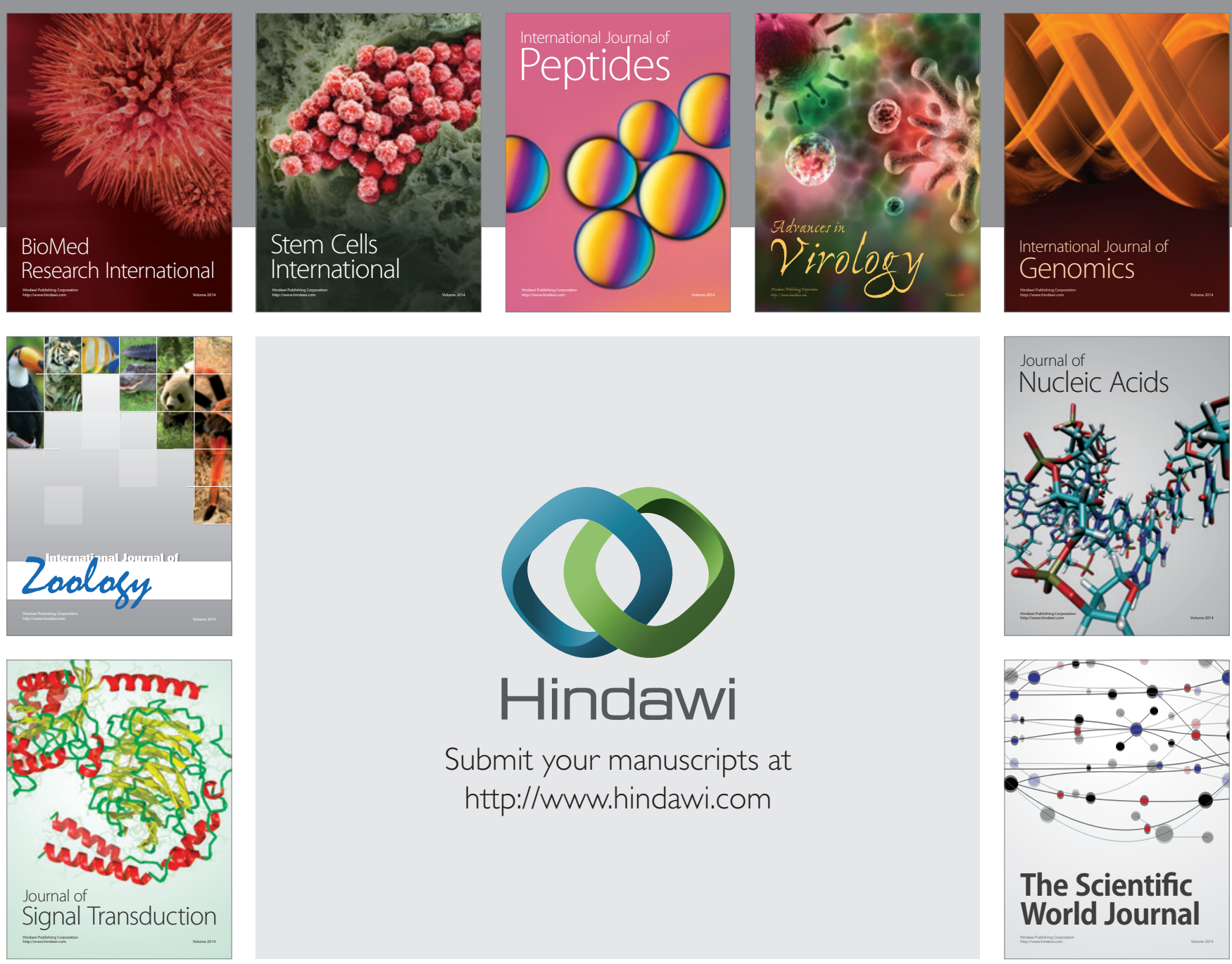

Submit your manuscripts at

http://www.hindawi.com
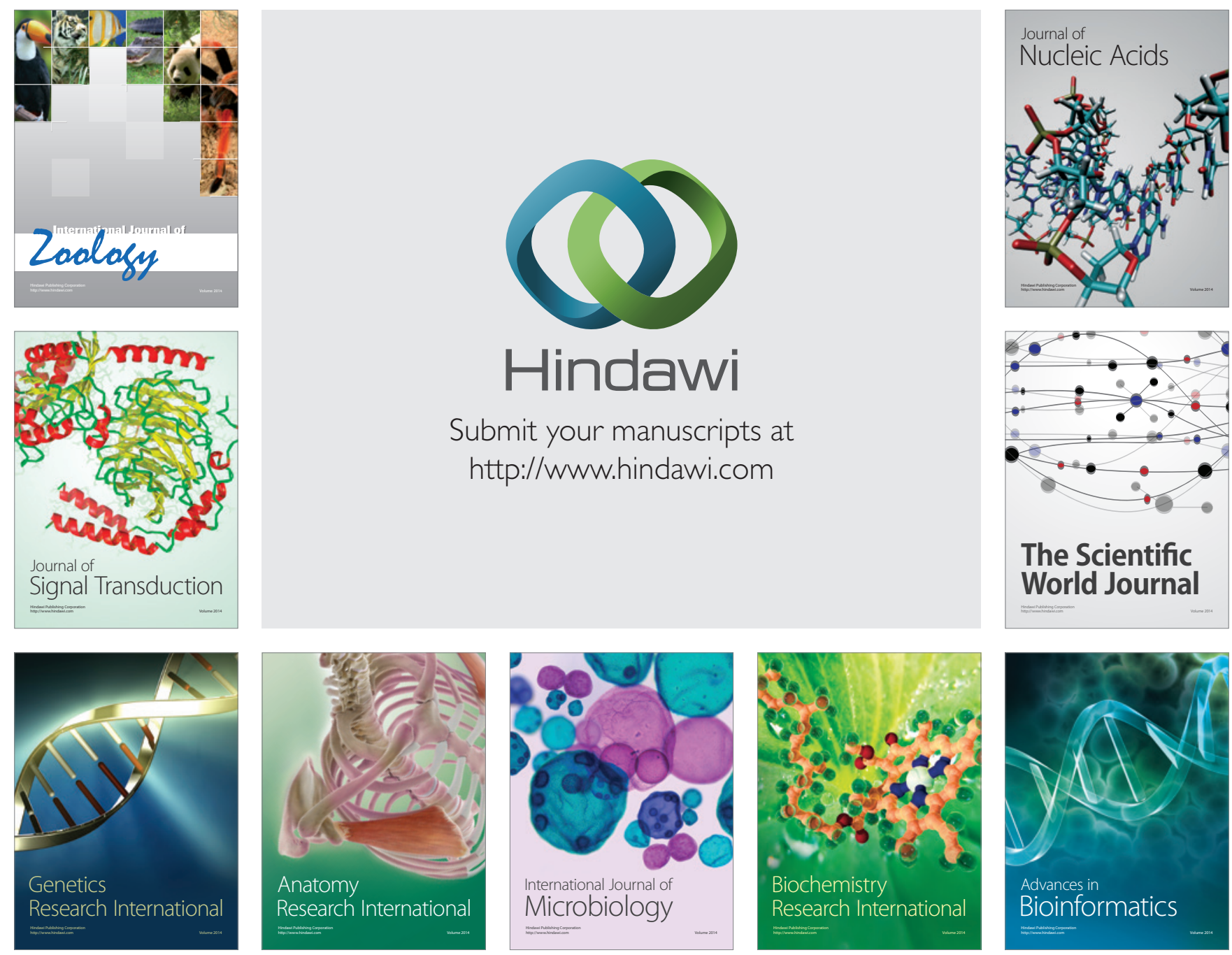

The Scientific World Journal
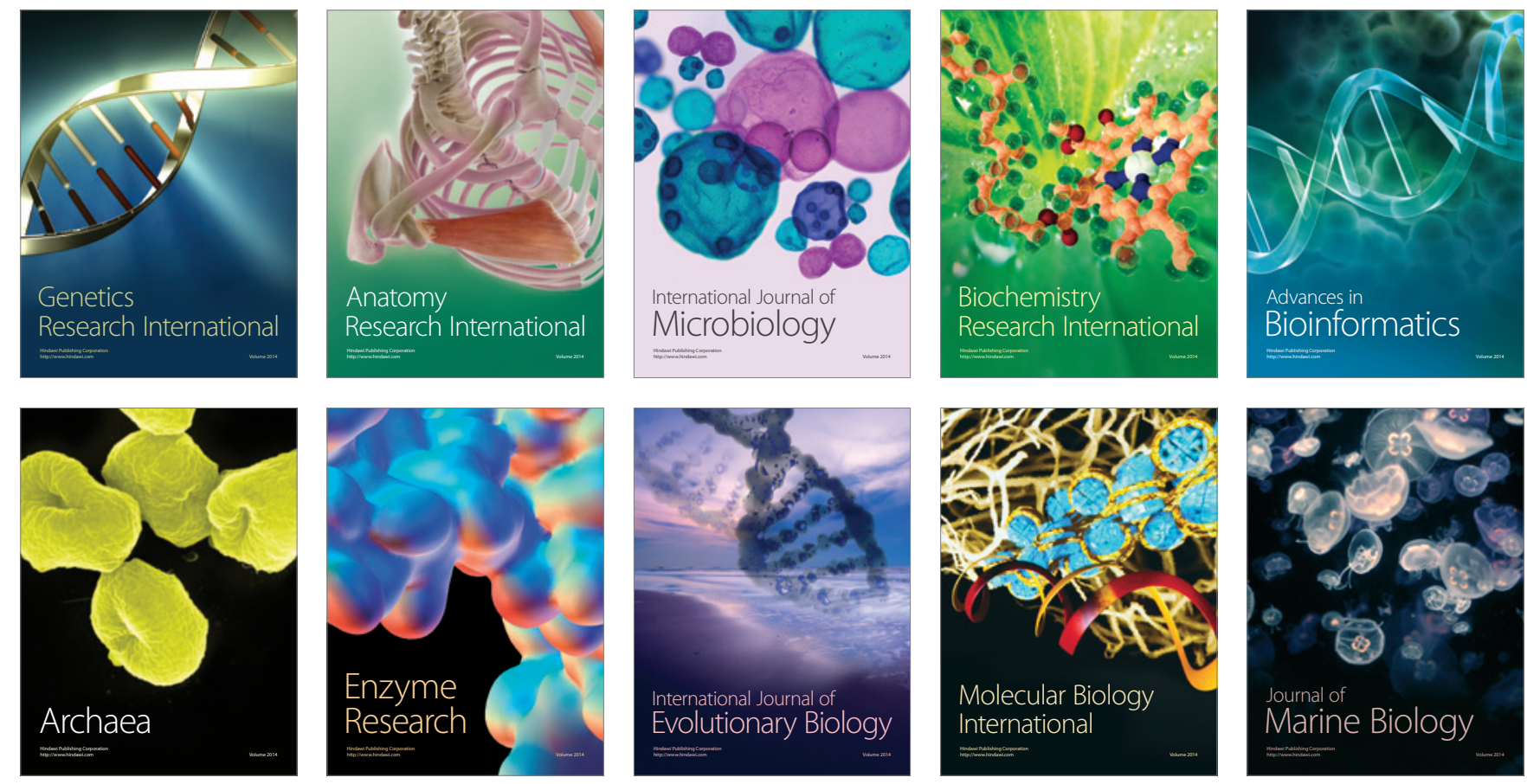